\title{
(Arte)
}

\section{Espacios para el arte, anotaciones para su configuración}

"Ya no hay que contestar a la pregunta ¿dónde ir?,

Por Leonel De Gunther D.

Universidad de Sonora

Departamento de Bellas Artes

leonel.degunther@unison.mx sino a esta otra. ¿dónde estás?”

Michel Serres

\section{Introducción}

El espacio puede ser pensado y ocupado de muy diversas maneras. Las diferentes formas de nombrarlo ponen de manifiesto la idea de espacio como una metáfora que expresa "un lugar": espacio público, espacio privado, espacio geométrico, espacio educativo, espacio urbano, espacio rural, espacio cultural, espacio familiar, espacio artístico, espacio virtual, etc.; para estar ahí, en él, para ocuparlo.

En un sentido general, el espacio supone la existencia de mapas para transitarlo o en su defecto, la posibilidad para inventarlos en sus límites y fugas (Serres, 1995). Incluso, algunas enfermedades dibujan mapas o atlas expresados a través de metáforas: a diferencia de la tuberculosis que se expresa como una metáfora temporal; el cáncer lo hace a través de una espacial (Sontang, 2003); donde su característica principal pone en el centro

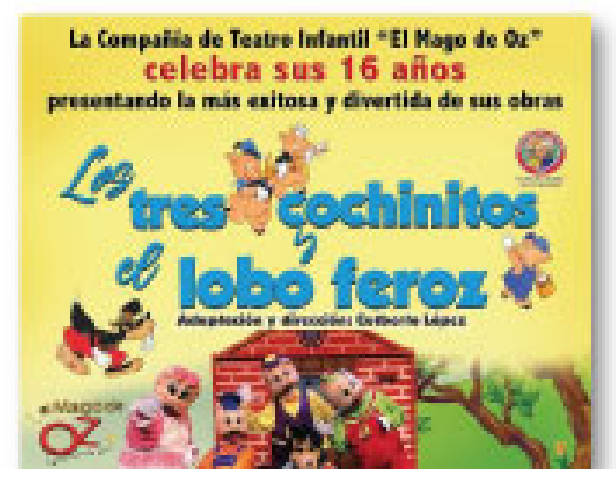

coordenadas de esta especie: se extiende, ramifica, expande, difunde.

Las ideas anteriores reflejan la noción de espacio como ser/estar en un lugar donde uno o algo está, cuando se mira aquí, ahí o allá, una idea bosquejada en el epígrafe que acompaña este texto, ¿estar dónde? ¿En dónde estamos cuando estamos ahí? ¿Quién o qué está ahí? También expresan las lógicas que intentan pensarlo y la ceguera constructiva que las acompaña. El propósito de este ensayo es ofrecer algunas anotaciones para pensar los espacios para el arte. "Mirar", "Ser / "Estar" en el espacio permite delimitar una comarca para el arte, en el que esté presente el pensamiento, el cuerpo y la política.

\section{Mirar el espacio}

El espacio ha sido pensado desde diferentes lógicas, en las disciplinas lo encontramos como espacio geométrico (físico)

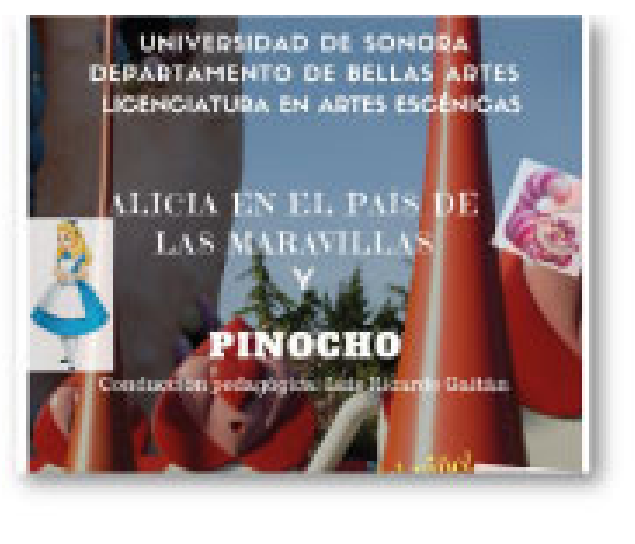


o existencial y en la vida como un estar juntos-ahí. Resulta entonces conveniente elaborar alguna forma para pensarlo y ligarlo al arte, empleando algunas ideas en que ha sido explicado o comprendido.

Pensar el espacio hoy conlleva una sutil distinción entre el espacio matematizado y escalar de la física o de las matemáticas: un espacio físico o magnitud; y el de la creación del espacio a efecto de disponer de él para crearlo y habitarlo: un espacio vital, significativo y público (Heidegger, 2009), incluso, como espacio percibido, soñado y practicado, vivido y usado (Delgado, 2007), pensarlo como paisaje social.

Pensar los espacios para el arte implica esta distinción. Por un lado, las magnitudes y coordenadas de un espacio que se cubre y ocupa y por el cual se transita, por otro lado, el encuentro de la creación y el logro humano en un espacio de interacción pública. En las artes plásticas el espacio se ocupa a través de la composición, las formas, el color; en la danza, se cubre con el cuerpo y su extensión y en la música, con su reverberación, coordenadas espaciales que albergan volúmenes, movimientos y sonidos. El arte ocupa el espacio sea como magnitud, como creación y como logro humano en interacción. En las artes plásticas, a diferencia de las escénicas y la música, la obra se configura en el espacio cuya materialidad se pone al frente, al final de la creación (Arendt, 2009), un espacio ausente de tiempo, que

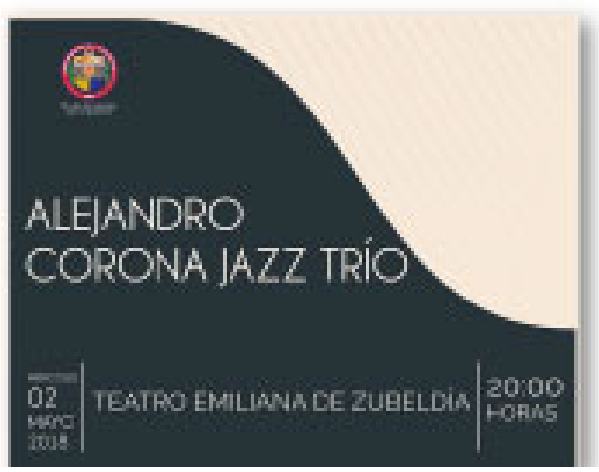

bien dibuja el desarrollo de la teoría estética. Sin embargo, hay también otro espacio, el que lo alberga, cobija y proyecta: la plaza pública; que pone la singularidad de un sujeto en contacto con la obra y en interacción con otros sujetos.

En ambos casos, el espacio -topología-, tiene dirección, área, forma, diseño, volumen, distancia y vacíos que lo materializan y permiten su apropiación tanto objetiva como subjetiva y expresa, a la vez, conectividad y continuidad. El espacio para las artes visto así configura un espacio doble: el de la obra creada como tal y el espacio que ocupa su presentación, dimensiones que sostienen un vínculo denso y frágil con la ciencia y la política, pero también la dificultad de su apropiación.

La dimensión des-articuladora de este vínculo, la ceguera constructiva, se debe probablemente a las disciplinas, a su escisión original derivada de sus objetos, propósitos y problemas de estudio. Una escisión que desune y desarticula, que paradójicamente nos permite conocer cada vez más la parte, el fragmento de lo conocido; pero constriñe con ello sus posibilidades de integración al todo del que es una parte o quizá, podríamos decir, poseo los conocimientos, las habilidades para la construcción de un pasaje entre las disciplinas, pero carezco de interés para ello (Agamben, 1999), la im-potencia de las disciplinas para entrar en diálogo entre ellas.

Así, la noción de espacio sea como mag-

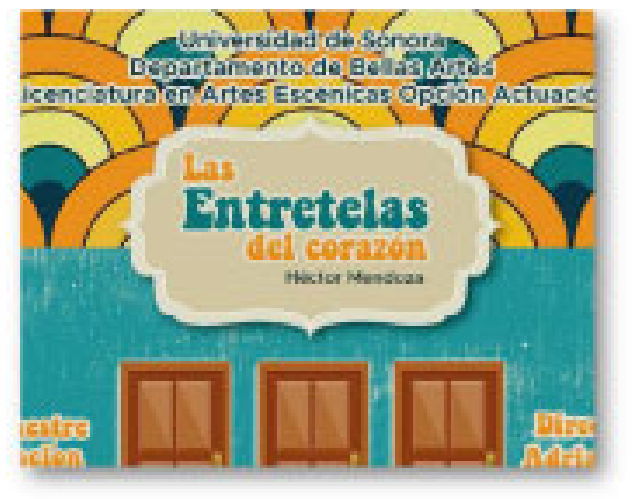




\section{(Arte)}

nitud o existencia, se expresa en la diversidad de concepciones dispersas y disponibles en las disciplinas y también en la vida: la noción de "espacio-tiempo" obtuvo su estatuto de cientificidad en las matemáticas y en la física en los inicios del siglo pasado; mientras que en las humanidades y en las ciencias sociales tales conceptos se consideran separados e interdependientes desde el siglo XIX (Harvey, 1998).

En las ciencias naturales el tiempo es una constante universal: ¿cuál es la velocidad de la luz? Y está especializado: ¿cuánto tiempo tarda un cuerpo en recorrer una distancia específica? Ambas entidades deben su existencia a la materia, solo a través del estudio de la materia podemos fundar nuestros conceptos de tiempo y de espacio, de aquí su condición objetiva y la primacía del tiempo sobre el espacio; mientras que en las humanidades y las ciencias sociales, el espacio se convierte en la condición que prima sobre el tiempo, su estetización, pero también en un lugar para la acción, un lugar de interacción en la plaza pública, un lugar de encuentro con los otros en el mundo de la vida: es a través de las prácticas materiales de los individuos en una sociedad o cultura que podemos dar cuenta de la diversidad de formas en que se objetiva el tiempo y el espacio y, a la vez, de su variedad en cada una de ellas: el tiempo de los seres humanos se mide en años, el de la iglesia; en siglos; mientras que la hora, el minuto, el segundo y el nanosegundo necesitan del espacio representado por la carátula del reloj o de un dispositivo para su presentación. Incluso, debemos a los cartógrafos de la edad media la estetización del espacio, la imagen ptoloméica: simetría y proporción adecuadas. Con ello, en un plano más amplio, encontramos el entrelazamiento de las nociones objetivas y subjetivas del espacio.

\section{Estar/Ser en el espacio y el tiempo}

Vivimos el espacio en nuestro estar en él, en nuestra creación incesante de él, es un estar-lo viviendo permanentemente. Estamos en el espacio, quizá, a la manera de una creencia, como lo ha expresado Ortega y Gasset (1959), presuponemos su existencia, cada enunciación desde el cuerpo: "espacio público" o "espacio privado"; pone al frente su existencia, pero al pensarlo que es siempre un re-pensar, al reflexionar sobre él, elaboramos distinciones y creamos espacios diferenciados: el que estamos viviendo y la manera en que lo pensamos, sin duda separamos cada uno de ellos a través de un proceso de humana abstracción, ideas y creencias se separan; pero sin lugar a dudas, emerge de nueva cuenta el vínculo entre nuestra forma de pensar y estar en el espacio.

Así, en el espacio matematizado hay "vacíos", discontinuidad que operan como

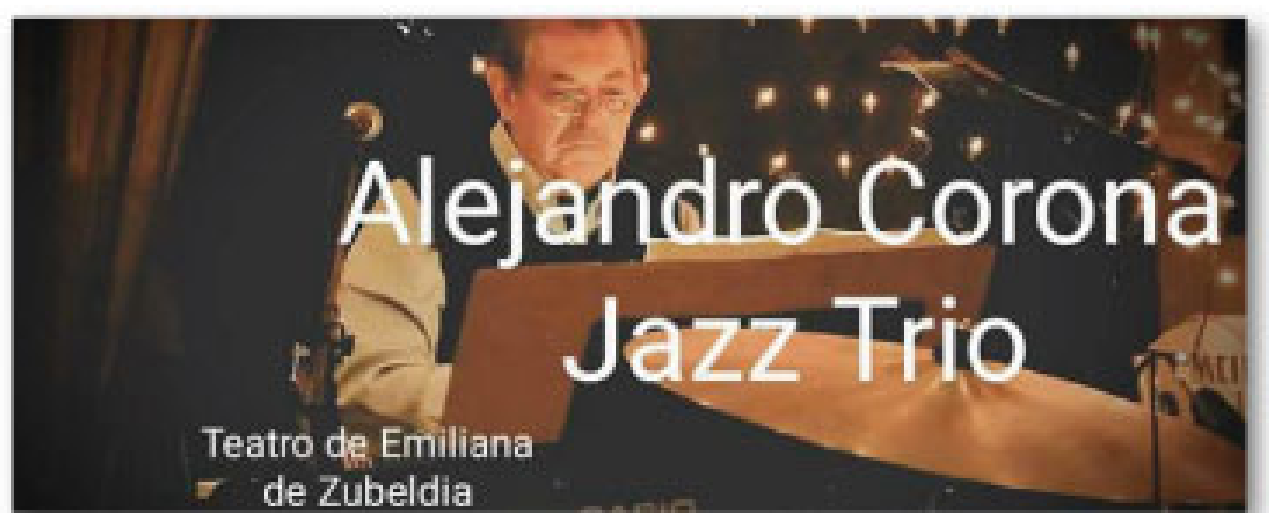




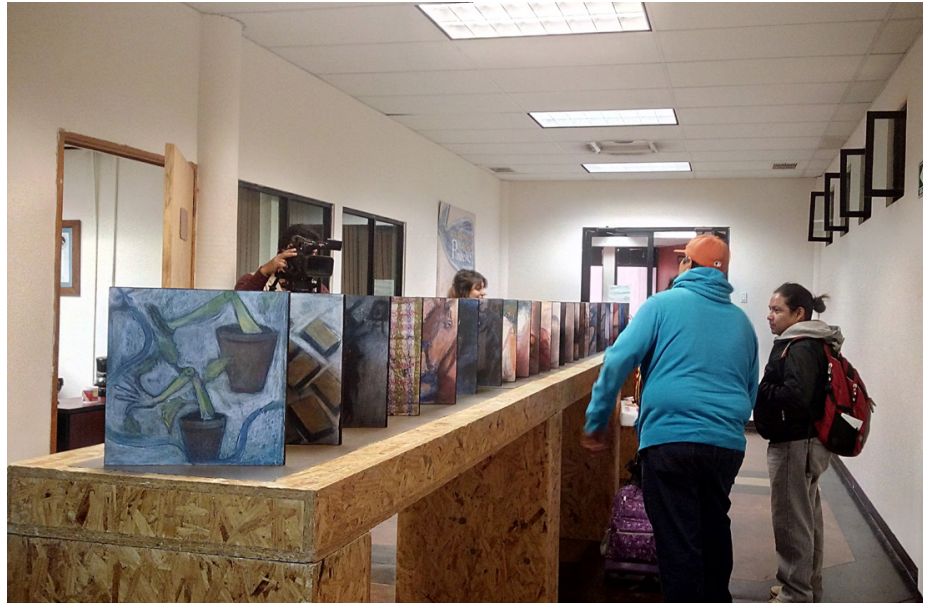

función cero, imposible de graficar (Pizarro, 1998), pero en la plástica, el vacío forma parte indisociable de la composición, un proceso similar ocurre con el cuerpo y la voz en la danza, el teatro y la música: los vacíos se ocupan. De aquí la emergencia de espacios continuos y discontinuos sea en la ciencia, el arte o en la política, orden y desorden son ahora constitutivos de la vida, configuran una articulación que retro-actúa a través de sus influencias mutuas y co-genera nuevos y complejos órdenes cuyo carácter expansivo se extiende, ramifica a todos los espacios de la vida (Morín, 2006).

Habitamos un espacio de dimensiones múltiples: lo finito e infinito, lo infinitamente pequeño del mundo, del ser humano frente a lo infinitamente grande el cosmos como lo habría sentido Pascal (como se cita en Buber, 1967). Las magnitudes y la existencia se nos presentan como un espacio material y existencial que ocupamos, creamos y estamos en él. Es por esto que ahora enfatizamos en el espacio vital, significativo y público o quizás singular, que bien podemos reelaborar a través de nuestra constante creación y producción de espacios para habitarlos, para estar en ellos, el espacio de la plaza pública que construimos juntos. Podemos expresarlos como nicho, cueva, tumba, comarca, casa, ciudad, desde una lógica que exprese su continuidad y discontinuidad, orden y desorden como constitutivos del espacio humano en la esperanza de dar consistencia a la inconsistencia que tal artificio constructivo hace emerger más allá de nuestro control.

El vientre es el nicho cóncavo originario, el espacio que nos alberga y materializa la vida; pero es también espacio temporal que nos expulsa a ningún lugar, hacia afuera, nos desarraiga y nos condena a construir, a buscar espacios donde vivir, una cueva, espacio también cóncavo y atávico, como refugio durante la vida luego de la expulsión originaria y un espacio para depositar los restos después de nuestra partida, la tumba como un espacio de nuestra consciencia de nosotros como seres humanos. Pero también construimos

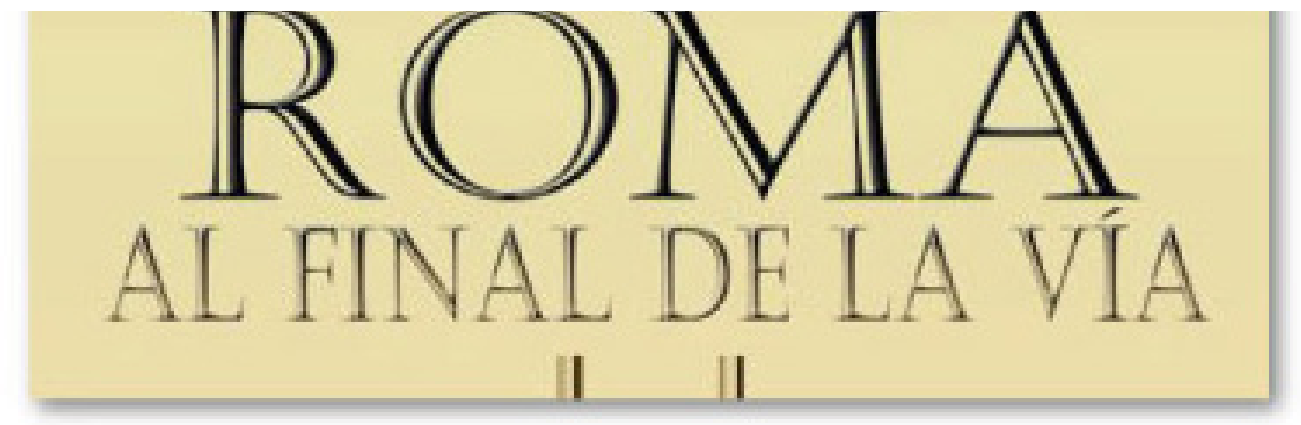


una comarca, delimitamos y limpiamos nuestro espacio, nuestro espacio colectivo para habitarlo y estar en él. La comarca emplaza en un doble sentido: abre el espacio para ocuparlo, lo ornamenta cosméticamente -crea mundos para habitarlo para evitar la inmundicia, el no-mundo-, $\mathrm{y}$ asiste a quienes quieran compartirlo con su diversidad, desde un nosotros inclusivo. Surge así, en el espacio delimitado en la comarca, el espacio físico delimitado dentro de ella, la casa, la vivienda, pero también el espacio existencial del hogar. Con la creación y ocupación de estos espacios en la comarca se levanta la ciudad y organiza sus espacios para habitarla, la plaza pública como espacio de la interacción humana y espacios en fuga hacia otras ciudades y comarcas. Surge un atlas, una cartografía para navegar los espacios de encuentro entre las ciudades y las comarcas y entre nosotros. Sin embargo, el espacio virtual deslocaliza nuestro estar, ¿en dónde estamos cuando estamos ahí? Un proceso de territorialización y desterritorialización se entreteje nuevamente, lo local y lo global se entrecruzan, lo abstracto y lo concreto también, cogenerando de nueva cuenta formas de pensar, sentir y estar en el espacio.

\section{La configuración del espacio para las artes}

Las observaciones que hemos elaborado sobre "mirar" el espacio y "ser / estar" en el espacio nos permiten pensar los espacios para el arte plástico -y no sólo para él- como espacios que no sólo se crean y recrean; sino que introducen además a un sujeto humano no gramatical, que configura un vínculo entre el pensamiento como poética, el cuerpo como ética y la interacción en la plaza pública como política. La poética crea espacios, el cuerpo los habita y la política los pone en relación, separarlos, reducirlos uno al otro, es empobrecer nuestro pensamiento sobre nosotros mismos. Se entrecruza aquí la imaginación poética que hace emerger nuevos lugares, nuevos nosotros. No hay que pensar tan pobremente a la humanidad, habría dicho Romain Gary (como se cita en Morin, 1999).

Se trata entonces, del esfuerzo del pensamiento, del espíritu humano por pensar de manera compleja, de articular, de unir sin sinterizar, de conservar la diferencia:

Pensar de forma compleja es pertinente ahí donde hay que pensar, donde no se puede reducir lo real ni a la lógica ni a la idea, donde no se puede ni debe racionalizar, donde buscamos algo más de los sabido por anticipado, donde buscamos no sólo inteligibilidad, sino también inteligencia (Morin, 2002, pp. 24-25).

Pensar una comarca para el arte consiste en delimitar un espacio, habilitarlo para estar en él y demarcarlo como comu-

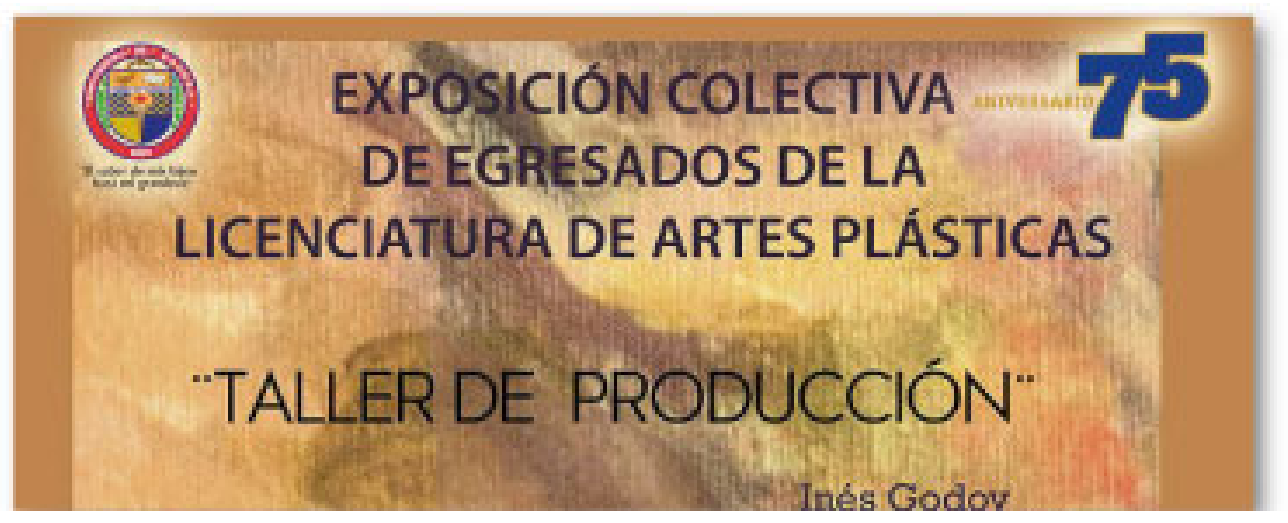


nidad vital y significativa, constituida por un nosotros humano inclusivo, dotada del valor humano que tienen los espacios en posesión y queridos por todos nosotros (Bachelard, 2000). El espacio para el arte se fuga a otros planos, deslocalizado constituye esa comarca abierta a la conformación de una comunidad de artistas (plásticos) que emplaza a su construcción para habitarlo con sus obras las cuales son por sí mismas espacios -aunque no sólo eso- y la comarca el espacio que expresa su conectividad, continuidad y discontinuidad entre ellas y los otros seres humanos y sus espacios, una comarca para el arte significa un espacio por construir y ocupar.

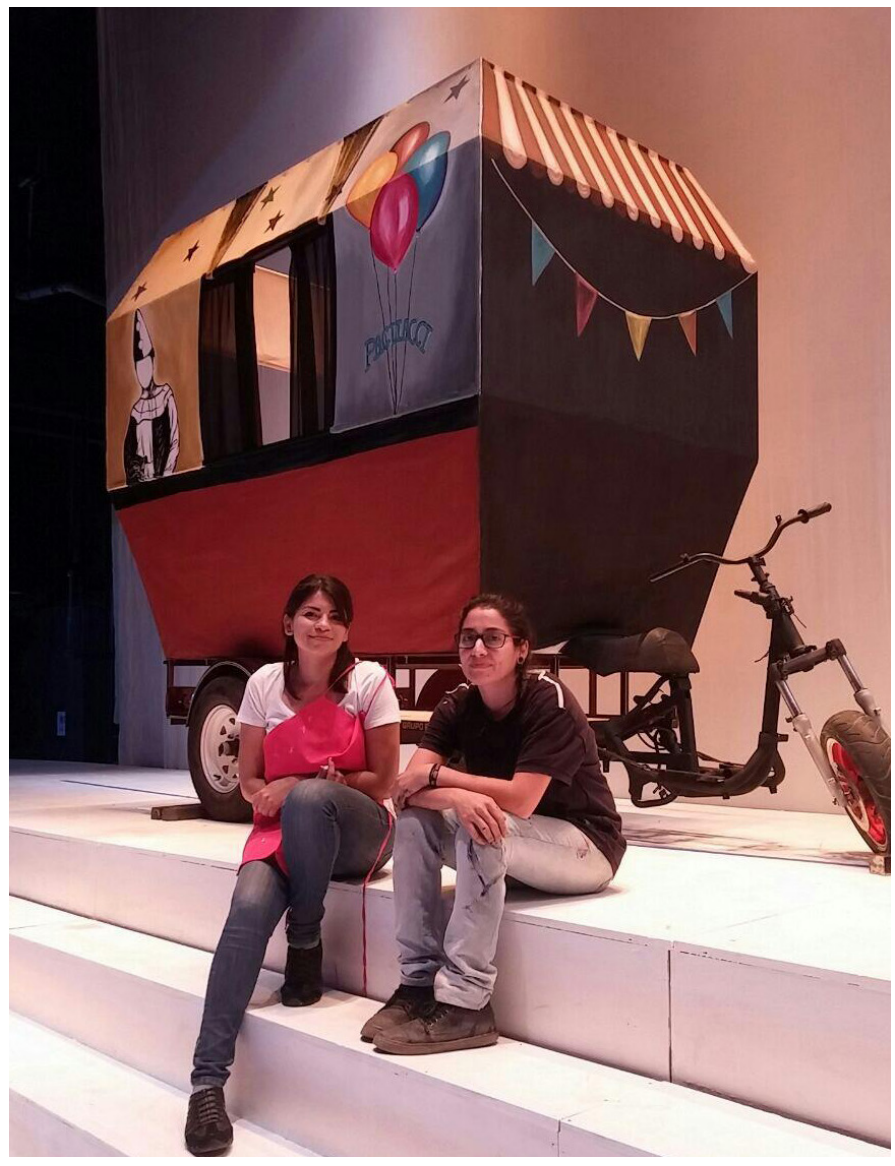

\section{A manera de conclusión}

El espacio puede ser pensado y ocupado de muy diversas maneras, sea a partir de las disciplinas o de la vida cotidiana. Puede ser pensado a través de su materialidad, de su geometrización, de su creación, incluso a partir de su estar en él viviéndolo, sintiéndolo, sin dejar de lado su virtualidad deslocalizadora. Tales for-

mas articulan una densa y frágil relación entre la ciencia y la política la cual exige un tipo de pensamiento relacional, uno que separe, pero también una, que organice sin totalizar, que analice sin sintetizar, uno que reconozca que el sentido está en la relación.

Se trata entonces de dotar de sentido nuestras formas de pensar el espacio para el arte, en su complejidad o tejido en con-

\section{UNIVERSIJAD DE SUNORA DEPARTAMENTU BELLAS ARTES \\ LICENCIATURA EN ARTES ESCENICAS OPCION DANZA CONTEMPORANEA}
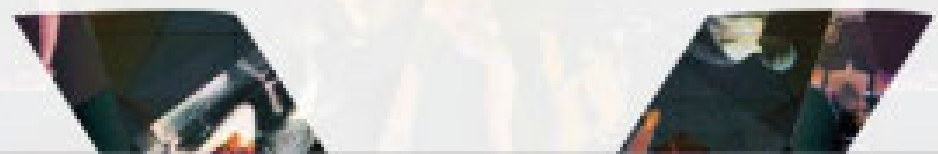


\section{(Arte)}

junto, que ponga en relación el pensamiento, el cuerpo y la política de manera compleja.

Pensar un espacio para las artes implica siempre una dimensión poética que lo construye como parte del propósito humano creativo, en ocasiones cargado de esa ceguera constructiva fuente del error y la ilusión, también humana. Implica, además, un cuerpo que lo habita y dota de un pulso emocional desarraigado, pero con límites éticos constitutivos de su forma de entrar en relación con los otros y sus creaciones y una política como espacio articulador, que constituye la dimensión del encuentro, el estar ahí con nuestros pensamientos y nuestros cuerpos singulares, juntos en la plaza pública.

\section{Bibliografía}

Agamben, G. (1999). Potencialities. Collected essays in Philosophy. Stanford, CA: Stanford University Press.

Arendt, H. (2009). La condición humana (R. Gil, Trans. 1a ed.). Buenos Aires: Paidós. Bachelard, G. (2000). La poética del espacio (E. d. Champourcín, Trans. 4ta ed.). Buenos Aires: Fondo de Cultura Económica.

Buber, M. (1967). ¿Qué es el hombre? (E. Imaz, Trans. 6a ed.). México: Fondo de Cultura Económica.

Delgado, M. (2007). Sociedades movedizas. Pasos hacia una antropología de las calles. Barcelona: Editorial Anagrama.

Harvey, D. (1998). La condición posmoderna. Investigación sobre los orígenes del cambio cutlural (M. Eguía, Trans. 1a ed.). Buenos Aires: Amorrortu editores.

Heidegger, M. (2009). Die kunst und der raum/El arte y el espacio (J. Escudero, Trans. 1a ed.). Barcelona: Herder.

Morin, E. (1999). Los 7 saberes necesarios para la educación del futuro (M. Vallejo-Gómez \& F. Girard, Trans.). París: Unesco.

Morin, E. (2002). Sociología (J. Tortella, Trans. 1a ed.). Madrid: Tecnos.

Morín, E. (2006). El metodo 4. Las ideas. Su hábitat, su vida, sus costumbres y su organización (A. Sánchez, Trans. 4ta ed. Vol. IV). Madrid: Cátedra.

Ortega y Gasset, J. (1959). Ideas y creencias. Madrid: Revista de Occidente.

Pizarro, N. (1998). Tratado de metodología de las Ciencias Sociales (1era ed.). Madrid: Siglo XXI de España editores.

Serres, M. (1995). Atlas (A. Martorell, Trans. 1a ed.). Madrid: Cátedra-Teorema.

Sontang, S. (2003). La enfermedad y sus metáforas (M. Muchnik, Trans. 1a ed.). Buenos Aires: Taurus pensamiento.
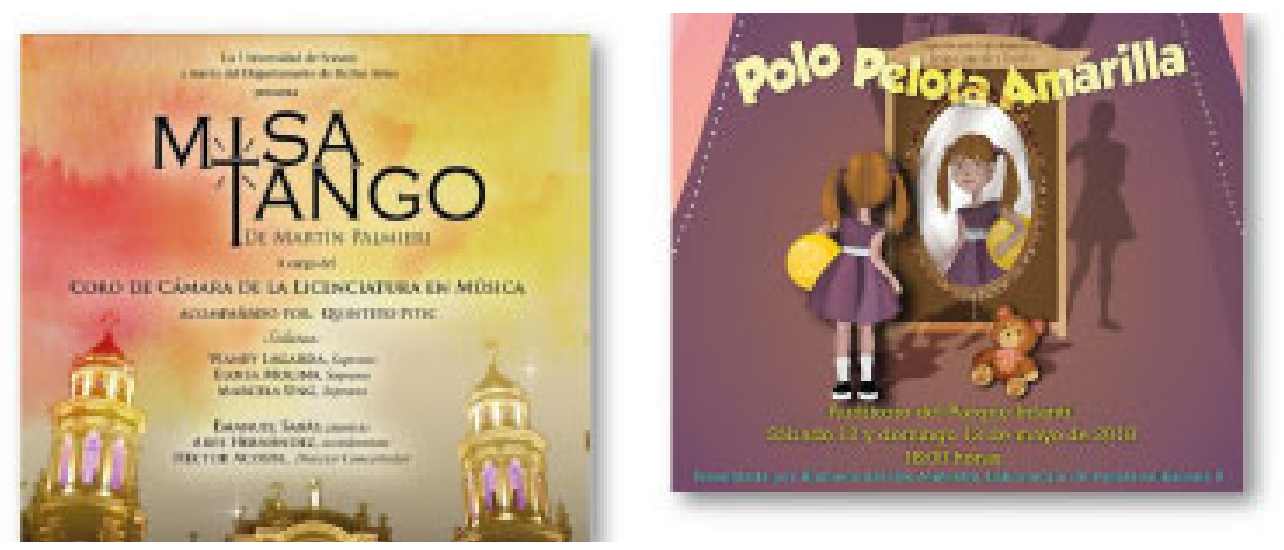